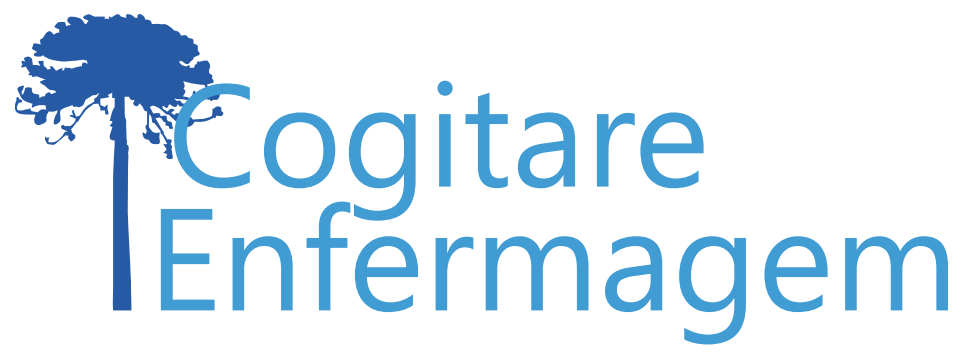

\title{
ESPIRITUALIDADE E RELIGIOSIDADE NO CUIDADO EM SAÚDE: REVISÃO INTEGRATIVA
}

Priscila Cristina da Silva Thiengo ${ }^{1}$, Antonio Marcos Tosoli Gomes ${ }^{2}$, Magno Conceição das Mercês ${ }^{3}$, Pablo Luiz Santos Couto ${ }^{4}$, Luiz Carlos Moraes França ${ }^{5}$, Alba Nunes da Silva ${ }^{6}$

\section{RESUMO}

Objetivo: descrever como a saúde, espiritualidade e religiosidade são abordadas nas publicações científicas nacionais.

Método: revisão integrativa de literatura no período entre 2011 e 2016, realizada na Biblioteca Virtual em Saúde em novembro de 2017, utilizando os descritores: "Saúde", "Espiritualidade", "Religiosidade".

Resultados: para a análise, segundo os critérios de inclusão estabelecidos, foram selecionados 30 artigos e identificadas quatro categorias: Conceitos e concepções de religiosidade e espiritualidade; Religiosidade e espiritualidade como estratégias de enfrentamento da doença; Necessidade de suporte espiritual; e Falta de preparo profissional. Verificou-se a relevância da dimensão espiritual na assistência e a necessidade de integralizar todas as dimensões do ser humano: biopsíquica, espiritual e social.

Conclusão: foram encontrados estudos que sugerem que algumas práticas religiosas são capazes de proporcionar tanto aspectos positivos quanto negativos na saúde física e mental dos seus praticantes.

DESCRITORES: Espiritualidade; Religião; Cuidado; Saúde; Revisão.

COMO REFERENCIAR ESTE ARTIGO:

Thiengo PCS, Gomes AMT, Mercês MC, Couto PLS, França LCM, Silva AB. Espiritualidade e religiosidade no cuidado em saúde: revisão integrativa. Cogitare enferm. [Internet]. 2019 [acesso em "colocar data de acesso, dia, mês abreviado e ano"]; 24. Disponível em: http://dx.doi.org/10.5380/ce.v24i0.58692.

Este obra está licenciado com uma Licença Creative Commons Atribuição 4.0 Internacional.

${ }^{1}$ Enfermeira. Doutoranda em Enfermagem. Docente de Enfermagem da Universidade do Estado do Rio de Janeiro. Rio de Janeiro, RJ, Brasil. 웅

${ }^{2}$ Enfermeiro. Doutor em Enfermagem. Docente de Enfermagem da Universidade do Estado do Rio de Janeiro. Rio de Janeiro, RJ, Brasil. $\odot$

Enfermeiro. Doutorando em Ciências da Saúde. Docente da Universidade do Estado da Bahia. Bahia, BA, Brasil.

${ }^{3}$ Enfermeiro. Mestre em Enfermagem. Docente da Faculdade Guanambi. Bahia, BA, Brasil. $\odot$

${ }^{5}$ Enfermeiro. Mestre em Enfermagem. Universidade do Estado do Rio de Janeiro. Rio de Janeiro, RJ, Brasil. $\odot$

${ }^{6}$ Enfermeira. Mestranda em Enfermagem. Universidade do Estado do Rio de Janeiro. Rio de Janeiro, RJ, Brasil. 


\title{
SPIRITUALITY AND RELIGIOSITY IN HEALTH CARE: AN INTEGRATIVE REVIEW
}

\author{
ABSTRACT \\ Objective: describe how health, spirituality and religiosity are discussed in Brazilian scientific \\ publications. \\ Method: integrative literature review of the period between 2011 and 2016, developed in \\ the Virtual Health Library in November 2017, using the descriptors: "Health", "Spirituality", \\ "Religiosity". \\ Results: for the analysis, according to the established inclusion criteria, 30 articles were \\ selected and four categories were identified: Concepts and conceptions of religiosity and \\ spirituality; Religiosity and spirituality as strategies to cope with disease; Need for spiritual \\ support; and Lack of professional preparation. The relevance of the spiritual dimension in care \\ was verified, as well as the need to comprehensively consider all dimensions of the human \\ being: biopsychic, spiritual and social. \\ Conclusion: studies were found that suggest that some religious practices are capable of \\ offering both positive and negative aspects in the physical and mental health of their \\ practitioners.
}

DESCRIPTORS: Spirituality; Religion: Care: Health; Review.

\section{ESPIRITUALIDAD Y RELIGIOSIDAD EN LA ATENCIÓN DE SALUD: REVISIÓN INTEGRATIVA}

\author{
RESUMEN \\ Objetivo: Describir de qué manera la salud, la espiritualidad y la religiosidad son abordadas \\ en las publicaciones científicas nacionales. \\ Método: Revisión integrativa de literatura abarcando período de 2011 a 2016, realizada en \\ la Biblioteca Virtual en Salud en noviembre de 2017, utilizando los descriptores "Saúde", \\ "Espiritualidade" y "Religiosidade". \\ Resultados: Para el análisis, conforme los criterios establecidos, fueron seleccionados 30 \\ artículos, y se identificaron cuatro categorías: Conceptos y concepciones de religiosidad y \\ espiritualidad; Religiosidad y espiritualidad como estrategias para el enfrentamiento de la \\ enfermedad; Necesidad de apoyo espiritual; y Falta de preparación profesional. Se verificó \\ la relevancia de la dimensión espiritual en la atención y la necesidad de integrar todas las \\ dimensiones del ser humano: biopsíquica, espiritual y social. \\ Conclusión: Fueron encontrados estudios que sugieren que algunas prácticas religiosas tienen \\ la capacidad de brindar tanto aspectos positivos como negativos para la salud física y mental \\ de quienes las practican.
}

DESCRIPTORES: Espiritualidad; Religión, Cuidado; Salud; Revisión. 
A atenção voltada para a dimensão espiritual torna-se cada vez mais necessária à prática assistencial à saúde. Inúmeros estudos vêm sendo desenvolvidos relacionando a espiritualidade com o enfrentamento de doenças, promoção e reabilitação, demonstrando o interesse da comunidade científica em tentar compreender os mecanismos fisiológicos que expliquem a relação entre a religiosidade e a espiritualidade no cuidado à saúde.

Pensar em religiosidade/espiritualidade e saúde traz à tona seu aspecto relacionado à prática clínica diária, demonstrando que ainda existe uma grande lacuna entre o saber e o fazer. Isso revela a necessidade de mais pesquisas que avaliem a integração desses conceitos e a correlação positiva sobre a taxa saúde doença ${ }^{(1-2)}$.

Em uma revisão de literatura recente, constatou-se que as práticas espirituais, incluindo as religiosas, serviam como suporte e enfrenta $\neg$ mento diante do acometimento à saúde, tanto para o doente quanto para o familiar. Também foi possível observar que a espiritualidade contribui para interpretar a doença dando um sentido e um significado a ela ${ }^{(3)}$. Deste modo, este trabalho tem como objetivo descrever como os conceitos saúde, espiritualidade e religiosidade são abordados nas publicações científicas realizadas no cenário nacional.

Sua realização se justifica pela importância que essas temáticas têm assumido nos últimos anos na área da saúde, com o intuito de fornecer um panorama das publicações existentes sobre o tema, e torna-se relevante por contribuir com o aprimoramento de saberes sobre a dimensão espiritual do cuidado em saúde de uma maneira mais específica.

\section{MÉTODO}

O estudo propõe uma reflexão sobre o panorama atual das publicações acerca das temáticas saúde, espiritualidade e religiosidade. Para seu desenvolvimento, fez-se uso dos pressupostos da revisão integrativa da literatura(4). A questão norteadora foi: "Qual a produção científica existente no cenário nacional acerca da temática saúde, espiritualidade e religiosidade?"

Foi realizada busca por artigos científicos publicados em periódicos produzidos no Brasil e indexados nas bases Literatura Latino-Americana e do Caribe em Ciências da Saúde (LILACS), Medical Literature Analysis and Retrieval System Online (MEDLINE), Base de Dados em Enfermagem (BDENF) e Base de Dados Virtuais em Psicologia (BVS-Psi), no mês de novembro de 2017. Os descritores "Espiritualidade", "Religiosidade" foram combinados, por meio do conector booleano "AND", com o descritor "Saúde" nos idiomas português, inglês e espanhol.

Foram identificados 155 artigos, e a partir da leitura criteriosa de títulos e resumos, foram selecionados 67 artigos que atendiam aos seguintes critérios: a. Publicados entre 2011 e 2016; b. Apresentavam versão completa do estudo disponível on-line; c. Relacionavam os descritores da busca no resumo e no texto. Dos artigos identificados, trinta e sete foram excluídos por não estarem dentro dos critérios estabelecidos: vinte e um não atendiam o objetivo proposto, quatro eram dissertações, teses e cartas ao editor, sete não apresentarem respostas a questão de pesquisa ou estavam repetidos.

Finalmente, o corpus foi composto por 30 artigos e para viabilizar a análise, foi utilizado um formulário de coleta de dados, construído pelos próprios autores, com informações que contemplaram os objetivos do estudo: autor, ano de publicação, revista, título e principais conclusões. O processo de análise envolveu a apreciação crítica do material, tendo por base a questão de pesquisa, a razão e a finalidade de obtenção de respostas ${ }^{(5)}$. 
A população contemplada nos estudos foi: graduandos; crianças, adolescentes e idosos em situação vulnerável seja por motivo de doença, internação ou violência praticada por pares; pacientes com doenças crônicas (síndrome da imunodeficiência adquirida, doenças genéticas, acometimentos mentais e doenças cardiovasculares); e cuidados paliativos. O ano de maior concentração foi de 2013 com 11 publicações, seguido do ano de 2012 com sete. 2011, 2014, 2015 e 2016 tiveram três publicações cada. As áreas que mais publicaram sobre a temática foram psicologia e enfermagem, com nove e sete publicações, respectivamente. Apenas oito publicações foram internacionais. O Quadro 1 apresenta os principais dados de publicação dos estudos.

Quadro 1 - Síntese dos principais achados. Rio de Janeiro, RJ, Brasil, 2017

\begin{tabular}{|c|c|c|}
\hline Ano & Periódico & Principais conclusões \\
\hline 2011 & RevPsiqClin & $\begin{array}{l}\text { A importância da espiritualidade/religiosidade/crenças pessoais aparece } \\
\text { positivamente associada com a qualidade de vida na maioria de seus domínios }{ }^{(6)} \text {. }\end{array}$ \\
\hline 2011 & $\begin{array}{l}\text { Psic: Teoria } \\
\text { e pesq }\end{array}$ & $\begin{array}{l}\text { A universidade não proporciona as informações necessárias sobre o tema e as } \\
\text { principais barreiras ao abordar o assunto foram: medo de impor as próprias crenças, } \\
\text { falta de tempo e medo de ofender os pacientes }{ }^{(2)} \text {. }\end{array}$ \\
\hline 2011 & $\begin{array}{l}\text { Rev Latino- } \\
\text { am. }\end{array}$ & $\begin{array}{l}\text { Religião e espiritualidade são recursos relevantes aos quais idosos recorrem no } \\
\text { enfrentamento da hospitalização }{ }^{(7)} \text {. }\end{array}$ \\
\hline 2012 & $\begin{array}{l}\text { Comunic. } \\
\text { saúde e Ed. }\end{array}$ & $\begin{array}{l}\text { Foram observadas algumas relações que apontam para: enfrentamentos } \\
\text { religiosos positivos e/ou negativos no adoecimento, mudanças de pensamento } \\
\text { e comportamentos religiosos, assim como a importância da vivência religiosa na } \\
\text { maneira como os indivíduos elaboram suas narrativas de adoecimento }{ }^{(8)} \text {. }\end{array}$ \\
\hline 2012 & $\begin{array}{l}\text { Rev. Min. } \\
\text { Enf. }\end{array}$ & $\begin{array}{l}\text { O método freiriano possibilita a reconstrução do conhecimento com liberdade, } \\
\text { ética, descontração e amor pela educação em saúde }{ }^{(9)} \text {. }\end{array}$ \\
\hline 2012 & $\begin{array}{l}\text { Ciênc. } \\
\text { Saúde } \\
\text { Coletiva }\end{array}$ & $\begin{array}{l}\text { Os resultados apontaram para tradições culturais muito presentes no discurso médico } \\
\text { (a norma, a razão, a família e a religiosidade judaico-cristã). Tais noções imbricam-se } \\
\text { com aquelas trazidas pelas tradições religiosas e influenciam as percepções médicas } \\
\text { a respeito do paciente e de sua família(10). }\end{array}$ \\
\hline 2012 & $\begin{array}{l}\text { Rev. Bras. } \\
\text { Enf. }\end{array}$ & $\begin{array}{l}\text { Concluiu-se que a religião é uma dimensão que pode contribuir positivamente no } \\
\text { tratamento do paciente com doença mental(11). }\end{array}$ \\
\hline 2012 & Psico arq. & $\begin{array}{l}\text { A cultura converge no sentido da integralidade, no entanto, existe o perigo das } \\
\text { aproximações de saberes em situações de desigualdade de poder, que podem levar } \\
\text { à construção de novas hegemonias culturais }{ }^{(12)} \text {. }\end{array}$ \\
\hline 2012 & $\begin{array}{l}\text { Ciênc. } \\
\text { Saúde } \\
\text { Coletiva }\end{array}$ & $\begin{array}{l}\text { Os migrantes possuem, no grupo, além de serviços religiosos uma, rede de apoio } \\
\text { social. Entretanto, existe um poder eclesiástico que, indiretamente, exerce uma } \\
\text { ação regulatória na vida dos migrantes }{ }^{(13)} \text {. }\end{array}$ \\
\hline 2013 & Interface & $\begin{array}{l}\text { Identificou-se a abertura para a promoção da saúde baseada em direitos humanos, } \\
\text { compreendendo jovens como protagonistas na adaptação de códigos religiosos a } \\
\text { cada trajetória e contexto singulares }{ }^{(14)} \text {. }\end{array}$ \\
\hline 2013 & $\begin{array}{l}\text { Jornal Bras. } \\
\text { Psiq. }\end{array}$ & $\begin{array}{l}\text { Os indivíduos com experiências anômalas que buscam auxílio parecem constituir } \\
\text { uma população de risco para transtornos mentais ou problemas emocionais em } \\
\text { geral(15). }\end{array}$ \\
\hline 2013 & Psico USP & $\begin{array}{l}\text { Apresenta uma síntese analítica das principais questões apontadas na literatura } \\
\text { concernente às relações entre religiosidade e saúde mental(16). }\end{array}$ \\
\hline 2013 & $\begin{array}{l}\text { Rev. Esc. } \\
\text { Enf. USP }\end{array}$ & $\begin{array}{l}\text { Concluiu-se que a religiosidade é um recurso valioso no enfrentamento das crises da } \\
\text { vida cotidiana e um fator que interfere de maneira positiva na saúde física e mental, } \\
\text { principalmente das pessoas idosas }{ }^{(17)} \text {. }\end{array}$ \\
\hline
\end{tabular}




\begin{tabular}{|c|c|c|}
\hline 2013 & Psico USP & $\begin{array}{l}\text { Os participantes evidenciaram concepções positivas sobre a influência da } \\
\text { religiosidade/espiritualidade para a saúde }{ }^{(18)} \text {. }\end{array}$ \\
\hline 2013 & $\begin{array}{l}\text { Interação } \\
\text { Psico. }\end{array}$ & O bem-estar positivo foi assumido como evidência de saúde ${ }^{(19)}$. \\
\hline 2013 & $\begin{array}{l}\text { Est. } \\
\text { Psicologia }\end{array}$ & $\begin{array}{l}\text { Ficou demonstrada a relação entre religiosidade e qualidade de vida, ressaltando-se } \\
\text { que a dimensão da religiosidade se relacionou com os domínios psicológico, social } \\
\text { e ambiental de qualidade de vida(20). }\end{array}$ \\
\hline 2013 & $\begin{array}{l}\text { Rev. Bras. } \\
\text { Enf. }\end{array}$ & $\begin{array}{l}\text { As representações da religiosidade inseridas na prática do cuidar de pacientes } \\
\text { em processo de morte valorizam as crenças dos profissionais sobre a morte e seu } \\
\text { significado, permitindo elaborar mecanismos de enfrentamento }{ }^{(21)} \text {. }\end{array}$ \\
\hline 2013 & $\begin{array}{l}\text { Ciênc. } \\
\text { Saúde } \\
\text { Coletiva }\end{array}$ & $\begin{array}{l}\text { O enfrentamento religioso reforça o fatalismo presente na crença religiosa, mas } \\
\text { também colabora para minimizar a responsabilidade social pelo cuidado do idoso }{ }^{(22)} \text {. }\end{array}$ \\
\hline 2013 & $\begin{array}{l}\text { Rev. Bras. } \\
\text { Clin. Méd. }\end{array}$ & $\begin{array}{l}\text { As dimensões de religiosidade dos alunos moldaram o modo de entender esses } \\
\text { conceitos de forma significativa }{ }^{(23)} \text {. }\end{array}$ \\
\hline 2013 & $\begin{array}{l}\text { Saúde e } \\
\text { Sociedade }\end{array}$ & $\begin{array}{l}\text { As informações coletadas permitem afirmar que as práticas religiosas se constituem } \\
\text { em lugares de acolhimento, de cura e de saúde para aqueles que as buscam }{ }^{(24)} \text {. }\end{array}$ \\
\hline 2013 & Rev. Gaúcha & $\begin{array}{l}\text { O medo de impor pontos de vista religiosos aos pacientes é a principal barreira } \\
\text { relacionada ao assunto(25). }\end{array}$ \\
\hline 2014 & $\begin{array}{l}\text { Rev. Bras. } \\
\text { Gerontol. }\end{array}$ & $\begin{array}{l}\text { Infere-se que há associação positiva entre religiosidade e a qualidade de vida } \\
\text { relacionada à saúde dos idosos }{ }^{(26)} \text {. }\end{array}$ \\
\hline 2014 & $\begin{array}{l}\text { Rev. Bras. } \\
\text { Est. Pop. }\end{array}$ & $\begin{array}{l}\text { Ao que tudo indica, religião e religiosidade são variáveis culturais e sua influência no } \\
\text { comportamento sexual foi percebida pela maioria dos artigos }{ }^{(27)} \text {. }\end{array}$ \\
\hline 2014 & $\begin{array}{l}\text { Arq. } \\
\text { Catarin. } \\
\text { Méd. }\end{array}$ & $\begin{array}{l}\text { A maioria dos estudos relatam resultados inconclusivos, pouco expressivos e } \\
\text { não convincentes da Religiosidade e Espiritualidade na saúde dos pacientes com } \\
\text { doenças cardíacas }{ }^{(28)} \text {. }\end{array}$ \\
\hline 2015 & $\begin{array}{l}\text { Rev. Saúde } \\
\text { pública }\end{array}$ & $\begin{array}{l}\text { A religiosidade organizacional e intrínseca exerce efeito benéfico sobre a relação } \\
\text { entre idade, escolaridade e a qualidade de vida relacionada à saúde de idosos }{ }^{(29)} \text {. }\end{array}$ \\
\hline 2015 & $\begin{array}{l}\text { Rev. Bras. } \\
\text { Ativ. Física }\end{array}$ & $\begin{array}{l}\text { A religiosidade, independentemente da religião, mostrou-se associada à proteção } \\
\text { aos comportamentos de risco à saúde em um grupo de adolescentes }{ }^{(30)} \text {. }\end{array}$ \\
\hline 2015 & $\begin{array}{l}\text { Rev. Psic, } \\
\text { teoria e } \\
\text { prática }\end{array}$ & $\begin{array}{l}\text { Prática religiosa esteve associada com idade, lipodistrofia e indicativo de ansiedade. } \\
\text { Infere-se que a religiosidade seja benéfica para a saúde mental, especialmente em } \\
\text { pacientes ansiosos }{ }^{(31)} \text {. }\end{array}$ \\
\hline 2016 & CuidArt & $\begin{array}{l}\text { A busca pela religião e o uso da espiritualidade pelos cuidadores está muito presente } \\
\text { diante do enfrentamento do câncer infantil. Desse modo, o profissional de saúde } \\
\text { deve ser uma fonte de respeito e de apoio às crenças, à religião e aos valores dos } \\
\text { cuidadores familiares }^{(32)} \text {. }\end{array}$ \\
\hline 2016 & $\begin{array}{l}\text { Saúde e } \\
\text { Debate }\end{array}$ & $\begin{array}{l}\text { Alguns avanços e recuos podem ser identificados, entre eles, a necessidade } \\
\text { de pesquisas com grupos em contextos específicos; a criação e a validação de } \\
\text { instrumentos para mensurar até quando as vivências religiosas/espiritualidade } \\
\text { podem ser benéficas ou não no tratamento dos transtornos mentais }{ }^{(33)} \text {. }\end{array}$ \\
\hline 2016 & $\begin{array}{l}\text { Esc. Anna } \\
\text { Nery }\end{array}$ & $\begin{array}{l}\text { Evidencia-se que os enfermeiros reconhecem a importância da dimensão espiritual } \\
\text { no atendimento de pacientes sob cuidados paliativos }{ }^{(34)} \text {. }\end{array}$ \\
\hline
\end{tabular}

Os estudos analisados foram categorizados em quatro áreas, salientando os principais resultados encontrados a fim de sintetizá-los e direcionando os resultados a uma prática fundamentada em conhecimento científico. 


\section{Conceitos e Concepções de Religiosidade e Espiritualidade}

Apesar de serem tratados como sinônimos na maioria dos estudos, outros ${ }^{(6-7,11,25)}$ apontam dificuldade na realização de trabalhos com a temática da religiosidade e espiritualidade pela diversidade e complexidade das suas definições. Em termos gerais, os autores definem religiosidade como a adesão a crenças e a práticas relativas a uma instituição religiosa organizada e a espiritualidade como a afinidade estabelecida entre uma pessoa e um ser ou uma força superior na qual ela acredita. Ou seja, a religiosidade é o quanto um indivíduo acredita, segue e pratica uma religião ${ }^{(25)}$.

Existem dois tipos de religiosidade descritas: intrínseca e extrínseca. Na primeira, a religião tem um lugar central na vida do indivíduo, é seu bem maior ${ }^{(7,25)}$. Nela o indivíduo agrega diferentes parâmetros culturais, conceitos morais e ideais específicos que oferecem significado à existência humana. Na segunda, a religião está vinculada a um conjunto de atividades e crenças e é um meio utilizado para obter outros fins, como consolo, sociabilidade, distração e status ${ }^{(6-7,20,34)}$.

Apesar do grande número de evidências, o conceito de espiritualidade ainda não é consensual. A espiritualidade pode ser definida como uma busca pessoal para entender questões relacionadas ao fim da vida, ao seu sentido, as relações com o sagrado ou transcendente que, podem ou não levar ao desenvolvimento de práticas religiosas ou formações de comunidades religiosas ${ }^{(18,20,35)}$.

A religião caracteriza-se, ao longo do tempo e do espaço, como extremamente variável de um contexto cultural para outro, de um período histórico para outro, inclusive com marcante influência na organização e desenvolvimento inicial da assistência no campo da saúde em nosso país ${ }^{(36)}$. Porém, existe uma formulação multidimensional que descreve a religião em vários aspectos, sendo ela considerada um conjunto de crenças, leis e ritos que visam um poder que o homem considera supremo, do qual se julga dependente, com o qual pode entrar em relação pessoal e do qual pode obter favores ${ }^{(19)}$.

A atitude religiosa é medida pelo envolvimento dos indivíduos em práticas religiosas como orações, leituras de material religioso, adoção de crenças definidas a partir de uma tradição religiosa específica, participação em cultos e outras reuniões religiosas, etc. Essa opção se justifica pela pressuposição de que pessoas que apresentam uma atitude religiosa mais clara, com um envolvimento religioso significativo e bem definido, podem adotar as crenças religiosas como referenciais cognitivos importantes para as suas interações. Essas crenças podem ser orientadoras e definir posicionamentos cognitivos e comportamentais do indivíduo frente a situações de risco e eventos estressores. Além disso, ao serem orientadoras, podem promover segurança e senso de sentido para a existência ${ }^{(19)}$.

Espiritualidade diferencia-se do conceito de religião por ter um significado mais amplo. A religião é uma expressão da espiritualidade, e espiritualidade é um sentimento pessoal, que estimula um interesse pelos outros e por si, um sentido de significado da vida capaz de fazer suportar sentimentos debilitantes de culpa, raiva e ansiedade. Religiosidade e espiritualidade estão relacionadas, mas não são sinônimas. Religiosidade envolve um sistema de culto e doutrina que é compartilhado por um grupo, e, portanto, tem características comportamentais, sociais, doutrinárias e valorais específicas, representando uma dimensão social e cultural da experiência humana. Espiritualidade está relacionada com o transcendente, com questões definitivas sobre o significado e propósito da vida, e com a concepção de que há mais na vida do que aquilo que pode ser visto ou plenamente entendido ${ }^{(19,35-37)}$.

Religião é um sistema organizado de crenças, práticas, rituais e símbolos que facilitam a proximidade do homem com o sagrado. A espiritualidade, por sua vez, tem relação com a reflexão e a busca pessoal sobre o significado da vida com relação ao sagrado, que podem ou não estar atreladas a uma religião. 


\section{Religiosidade e espiritualidade como estratégias de enfrentamento da doença}

As estratégias de enfrentamento com base na religiosidade incluem o uso da religião, espiritualidade ou fé para lidar com o estresse e as consequências negativas geradas pela experiência dos problemas da vida. A religiosidade e a espiritualidade atribuem significado à experiência de adoecimento. Muitas vezes, são o único apoio encontrado para a compreensão e o enfrentamento das dificuldades impostas pelos sintomas e as formas de manejo das situações de estresse.

Diversos estudos têm investigado a relação entre religiosidade, espiritualidade e saúde ${ }^{(1-2,7-8,17,37)}$. A ligação entre eles está na identificação que as vivências religiosas e espirituais tinham correlação significantemente positiva sobre a taxa saúde doença. Esses resultados estão relacionados aos efeitos positivos na redução da mortalidade em geral, assim como nas áreas da imunologia, saúde mental, doenças cardiovasculares, doenças infecto parasitárias como o HIV e neoplasias ${ }^{(1-2)}$.

Esse resultado constitui subsídios alcançados pelas pessoas que buscam se fortalecerem diante das adversidades impostas pela condição patológica. Além da condição patológica, a religião pode exercer papel estabilizador e pode representar um fator influenciador para as relações sociais e familiares. Algumas práticas religiosas também são capazes de proporcionar aspectos positivos na saúde física e mental dos seus praticantes, na medida em que aconselham a adoção de hábitos e condutas saudáveis $(9,14,24,30)$.

Dentre os benefícios mencionados, está a influência na adaptação psicológica com o fortalecimento das emoções de conforto, suporte social, redução da carga emocional da doença com sua possível aceitação e o auxílio na preservação da saúde (6-28) $^{(6)}$ Evidências demonstram a associação positiva da religiosidade com a saúde mental, sendo considerada como fator protetor para o suicídio, abuso de drogas e de álcool, sofrimento psicológico e psicoses $(2,6,12,14,24)$.

O enfrentamento religioso é uma estratégia importante e regula a resposta emocional causada pelo processo de incapacidade funcional causada pela doença ou pela idade avançada, reparando o esvaziamento existencial, fazendo a pessoa sentir-se acolhida e apaziguada na realidade de seu corpo de hoje incapacitado ou envelhecido(17,22,26,38). Há também o apego dos cuidadores à fé. O sofrimento e o desgaste causado pela doença e a crença no milagre da cura podem se apresentar como uma fonte de apoio para o enfrentamento da doença e do seu tratamento ${ }^{(32)}$.

Mas há situações em que a busca religiosa pode piorar o quadro clínico, causando o enfrentamento negativo e o uso inadequado dos serviços de saúde. São aspectos negativos relacionados ao fanatismo e o tradicionalismo opressivo(11,15,27-28,33,39). A oposição ao tratamento proposto pelas instituições de saúde, principalmente quando relacionado à saúde mental, é bastante desafiadora por causar a inviabilidade do cuidado para as pessoas em sofrimento ${ }^{(16)}$. A rigidez e a inflexibilidade associadas à resistência ao tratamento podem dificultar a adesão e, com isso, tornar os pacientes vulneráveis ao abuso espiritual(11).

A religião pode afetar positivamente a saúde física e mental por meio de rede de apoio social, redução de comportamentos não saudáveis, redução da pressão arterial e tensão muscular durante oração e meditação, e maior adesão a tratamentos médicos e cuidados preventivos ${ }^{(14-15,39)}$.

\section{Necessidade de suporte espiritual e falta de preparo profissional}

Os pacientes muitas vezes descobrem força e consolo em sua espiritualidade, tanto informalmente através de conexões mais profundas com familiares e amigos, como formalmente através de comunidades e práticas religiosas. No entanto, os clínicos modernos ignoram regularmente as dimensões da espiritualidade quando se considera a saúde dos outros - ou mesmo a si mesmos. 
Durante muito tempo, os profissionais de saúde mental negavam os aspectos religiosos da vida humana, inclusive considerando patológico quando em se tratando de pacientes psiquiátricos. No entanto, estudos demonstram que a religiosidade é um aspecto de grande importancia na vida humana e possui associação positiva com boa saúde mental(40).

Talvez por isso, muitos profissionais ainda se sentem hesitantes e com pouca confiança para abordar estes aspectos, abarcados pela falta de inclusão adequada dessa temática durante o processo de formação acadêmica ${ }^{(25,37)}$. Sem modelos bem estruturados de avaliação e treinamento dos profissionais em formação, dificulta-se a introdução desse suporte na prática clínica diária, já tão sobrecarregada com funções administrativas e pelo pouco tempo disponível.

No entanto, como demonstram os estudos, diante de situações de doença, as pessoas tendem a expressar suas necessidades espirituais nas formas mais sutis. Sendo assim, tanto o doente quanto sua família podem se beneficiar da assistência espiritual se houver uma abordagem neste sentido.

Estudos internacionais apontam que muitos profissionais de saúde refletem sobre a necessidade de abordar e atender as necessidades espirituais de seus pacientes, independentemente de suas próprias crenças religiosas ou espirituais. No entanto, há desconforto nessa abordagem, visto que se sentem como se isso fosse além de seu papel como cuidador ${ }^{(41-42)}$.

Há divergência entre autores sobre o envolvimento do terapeuta nas questões religiosas sob o ponto de vista de colocar em risco a individualidade e a integridade do tratamento. Apesar da oração ser um fator de conforto e esperança, não há consenso se o profissional deve se manter em posição neutra ou defender e incentivar a vivência religiosa ${ }^{(43)}$. Ainda há a queixa recorrente em relação à formação acadêmica, durante a qual o assunto não é abordado, deixando uma lacuna entre os parâmetros de avaliação desse envolvimento ser benéfico ou não para a relação terapêutica.

Seguindo essa tendência, a NANDA International (NANDA I), ao atentar para o cuidado espiritual nos diagnósticos de Enfermagem, fornece estímulo à importância de um estudo formal acerca da temática Saúde e Espiritualidade na graduação. Alunos do curso de Enfermagem acreditam que a espiritualidade influencia na saúde de seus pacientes e no próprio atendimento por parte do enfermeiro e, apesar de a maioria desejar abordar esse aspecto, poucos se julgam preparados para tal(2). Notavelmente, mais de $90 \%$ dos alunos avaliados por esse estudo acreditam que a universidade não proporciona todas as informações necessárias para este preparo(25).

Os resultados apontam que os profissionais, de maneira geral, são favoráveis à criação de disciplinas que preparem o profissional sobre a temática religiosa/espiritual. No Brasil, são escassos os cursos que abordem em seus currículos conteúdos sobre a interface religião e/ou espiritualidade e a área da saúde, reservando-se o assunto para momentos práticos de ensino ${ }^{(39-41)}$.

A falta de treinamento e de habilidade em identificar as demandas dos pacientes impelem a negação ou a rejeição da dimensão espiritual. Percebe-se a falta de preparo e percepção dos profissionais, revelando a dificuldade em atender à demanda espiritual dos pacientes $(2,17,39)$. Entretanto, serão poucos profissionais que não terão contato com situações em que a religião poderá nortear condutas e até dilemas éticos.

Cabe mencionar que as limitações do estudo estão relacionadas ao baixo número de publicações sobre a temática abordada. Destaca-se a necessidade de mais pesquisas e reflexões sobre o que fazer para sensibilizar os profissionais de saúde, inclusive aqueles ainda em formação, sobre o tema e como lidar com suas tensões e compreensão. 
Verificou-se a relevância da dimensão espiritual na assistência e a necessidade de integralizar todas as dimensões do ser humano: biopsíquica, espiritual e social. Foi constatado que as práticas religiosas são capazes de proporcionar aspectos positivos ou negativos na saúde física e mental dos seus praticantes. Algumas barreiras são apontadas, como falta de tempo, falta de conhecimento e medo de impor suas crenças, demonstrando a insegurança e a falta de treinamento dos profissionais de saúde com relação a esse tema. Entretanto, poucos profissionais não terão contato com situações em que a religião poderá nortear condutas e até dilemas éticos.

Os autores ressaltam os conceitos de espiritualidade e religiosidade, demonstrando sua conexão e suas diferenças. Toda vivência espiritual transcende a religiosa com seu sistema de crenças, sendo necessário conhecê-la de modo a identificar sua interferência no tratamento, seja ele positivo ou negativo, para que se possa intervir, se necessário. É importante inclusive ouvir o que pensam a família e os líderes religiosos a respeito do tema, considerando-os como parceiros importantes na rede social de apoio ao paciente.

Conclui-se que há uma grande dificuldade de pesquisar e definir limites entre as relações saúde, doença, religião, religiosidade e espiritualidade, por serem fenômenos multifatoriais e multidimensionais, não sendo explicados completamente por suas ações e consequências. Fato é que a combinação de crenças e do envolvimento religioso age para determinar efeitos na saúde da pessoa religiosa, sejam positivos ou negativos.

\section{REFERÊNCIAS}

1. Portes LH, Guimarães MBL. Espiritualidade, religiosidade e religião e as políticas públicas de saúde em relação ao tabagismo. Rev APS. [Internet]. 2012 [acesso em 10 nov 2017]; 15(1). Disponível em: https:// aps.ufjf.emnuvens.com.br/aps/article/viewFile/1421/599.

2. Tomasso CS, Beltrame IL, Lucchetti G. Conhecimentos e atitudes de docentes e alunos em enfermagem na interface espiritualidade, religiosidade e saúde. Rev. Latino-Am. Enfermagem. [Internet]. 2011 [acesso em 10 nov 2017]; 19(5). Disponível em: http://dx.doi.org/10.1590/S010411692011000500019.

3. Santo CCE, Gomes AMT, Oliveira DC, Pontes APM, Santos El, Costa CPM. Diálogos entre espiritualidade e enfermagem: uma revisão integrativa da literatura. Cogitare enferm. [Internet]. 2013 [acesso em 11 jan 2018]; 18(2). Disponível em: http://dx.doi.org/10.5380/ce.v18i2.32588.

4. Mendes KDS, Silveira RCCP, Galvão CM. Revisão Integrativa: método de pesquisa para incorporação de evidências na saúde e na enfermagem. Texto contexto-enferm. [Internet]. 2008 [acesso em 10 nov 2017]; 17(4). Disponível em: http://dx.doi.org/10.1590/S0104-07072008000400018.

5. Soares CB, Hoga LAK, Peduzzi M, Sangaleti C, Yonekura T, Silva DRAD. Revisão integrativa: conceitos e métodos utilizados na enfermagem. Rev. esc. enferm. USP. [Internet]. 2014 [acesso em 27 out 2018]; 48(2). Disponível em: http://dx.doi.org/10.1590/S0080-6234201400002000020.

6. Rocha NS, Fleck MPA. Avaliação de qualidade de vida e importância dada a espiritualidade/ religiosidade/crenças pessoais (SRPB) em adultos com e sem problemas crônicos de saúde. Rev. psiquiatr. clín. [Internet]. 2011 [acesso em 10 nov 2017]; 38(1). Disponível em: http://dx.doi.org/10.1590/S0101$\underline{60832011000100005 .}$

7. Duarte FM, Wanderley KS. Religião e Espiritualidade de Idosos Internados em uma Enfermaria Geriátrica. Psic.: Teor. e Pesq. [Internet]. 2011 [acesso em 10 nov 2017]; 27(1). Disponível em: http://www. scielo.br/pdf/ptp/v27n1/a07v27n1.pdf.

8. Ferreira DC, Favoreto CAO, Guimarães MBL. The influence of religiousness on living with HIV. Interface. [Internet]. 2012 [acesso em 10 nov 2017]; 16(41). Disponível em: http://dx.doi.org/10.1590/ 
9. Ferreira AGN, Silva KL, Sousa PRM, Gubert FA, Vieira NFC, Pinheiro PNC. Cultura masculina e religiosidade na prevenção das DST/HIV/Aids em adolescentes. REME - Rev. Min. Enferm. [Internet]. 2012 [acesso em 10 nov 2017]; 16(4). Disponível em: http://pesquisa.bvs.br/brasil/resource/pt/bde-23940.

10. Martins AJ, Cardoso MHCA, Llerena JC, Moreira MCN. A concepção de família e religiosidade presente nos discursos produzidos por profissionais médicos acerca de crianças com doenças genéticas. Ciênc. saúde coletiva. [Internet]. 2012 [acesso em10 nov 2017]; 17(2). Disponível em: http://dx.doi. org/10.1590/S1413-81232012000200027.

11. Murakami R, Campos CJG. Religião e saúde mental: desafio de integrar a religiosidade ao cuidado com o paciente. Rev. bras. enferm. [Internet]. 2012 [acesso em 10 nov 2017]; 65(2). Disponível em: http:// dx.doi.org/10.1590/S0034-71672012000200024.

12. Lages SRC. Saúde da população negra: a religiosidade afro-brasileira e a saúde pública. Psicol. Argum. [Internet]. 2012 [acesso em 10 nov 2017]; 30(69). Disponível em: https://periodicos.pucpr.br/ index.php/psicologiaargumento/article/view/23295.

13. Matsue RY. "Sentir-se em casa longe de casa": vulnerabilidade, religiosidade e apoio social entre os migrantes brasileiros no Japão. Ciênc. saúde coletiva. [Internet]. 2012 [acesso em 10 nov 2017]; 17(5). Disponível em: http://dx.doi.org/10.1590/S1413-81232012000500007.

14. Da Silva CG, Paiva V, Parker R. Religious youth and homosexuality: challenges for promotion of health and sexual rights. Interface. [Internet]. 2013 [acesso em 10 nov 2017]; 17(44). Disponível em: http://dx.doi. org/10.1590/S1414-32832013000100009.

15. Alminhana LO, Menezes Junior A, Moreira-Almeida A. Personalidade, religiosidade e qualidade de vida em indivíduos que apresentam experiências anômalas em grupos religiosos. J. bras. psiquiatr. [Internet]. 2013 [acesso em 10 nov 2017]; 62(4). Disponível em: http://dx.doi.org/10.1590/S004720852013000400004.

16. Freitas $\mathrm{MH}$. Relações entre religiosidade e saúde mental em imigrantes: implicações para a prática psi. Psico-USF. [Internet]. 2013 [acesso em 10 nov 2017]; 18(3). Disponível em: http://dx.doi.org/10.1590/ $\underline{\mathrm{S} 1413-82712013000300010 .}$.

17. Zenevicz L, Moriguchi Y, Madureira VSF. A religiosidade no processo de viver Envelhecendo. Rev. esc. enferm. USP. [Internet.] 2013 [acesso em 10 nov 2017]; 47(2). Disponível em: http://dx.doi.org/10.1590/ S0080-62342013000200023.

18. Gobatto CA, Araujo TCCF. Religiosidade e espiritualidade em oncologia: concepções de profissionais da saúde. Psicol. USP. [Internet]. 2013 [acesso em 10 nov 2017]; 24(1). Disponível em: http://dx.doi. org/10.1590/S0103-65642013000100002.

19. Vieira TM, Zanini DS, Amorim AP. Religiosidade e bem-estar psicológico de acadêmicos de psicologia. Interação Psicol. [Internet]. 2013 [acesso em 10 nov 2017]; 17(2). Disponível em: http://dx.doi. org/10.5380/psi.v17i2.26678.

20. Medeiros B, Saldanha AAW. Religiosidade e qualidade de vida em pessoas com HIV. Estud. Psicol. [Internet]. 2012 [acesso em 10 nov 2017]; 29(1). Disponível em: http://www.scielo.br/pdf/estpsi/v29n1/ a06v29n1.pdf.

21. Abrão FMS, Góis ARS, Souza MSB, Araujo RA, Cartaxo CMB, Oliveira DC. Representações sociais de enfermeiros sobre a religiosidade ao cuidar de pacientes em processo de morte. Rev. bras. enferm. [Internet]. 2013 [acesso em 10 nov 2017]; 66(5). Disponível em: http://dx.doi.org/10.1590/S003471672013000500014.

22. Santos WJ, Giacomin KC, Pereira JK, Firmo JOA. Enfrentamento da incapacidade funcional por idosos por meio de crenças religiosas. Ciênc saúde coletiva. [Internet]. 2013 [acesso em 10 nov 2017]; 18(8).

Disponível em: http://dx.doi.org/10.1590/S1413-81232013000800016. 
23. Borges DC, Anjos GL, Oliveira LR, Leite JR, LucchettiG. Saúde, espiritualidade e religiosidade na visão dos estudantes de medicina. Rev. Bras. Clin Med. [Internet]. 2013 [acesso em 10 nov 2017]; 11(1). Disponível em: http://files.bvs.br/upload/S/1679-1010/2013/v11n1/a3380.pdf.

24. Mello ML, Oliveira SS. Saúde, religião e cultura: um diálogo a partir das práticas afro-brasileiras. Saúde Soc. [Internet]. 2013 [acesso em 10 nov 2017]; 22(4). Disponível em: http://dx.doi.org/10.1590/ S0104-12902013000400006.

25. Espinha DCM, Camargo SM, Silva SPZ, Pavelqueires S, Lucchetti G. Opinião dos estudantes de enfermagem sobre saúde, espiritualidade e religiosidade. Rev. Gaúcha Enferm. [Internet]. 2013 [acesso em 10 nov 2017]; 34(4). Disponível em: http://dx.doi.org/10.1590/S1983-14472013000400013.

26. Santos NC, Abdala GA. Religiosidade e qualidade de vida relacionada à saúde dos idosos em um município na Bahia, Brasil. Rev. bras. geriatr. gerontol. [Internet]. 2014 [acesso em 10 nov 2017]; 17(4). Disponível em: http://dx.doi.org/10.1590/1809-9823.2014.13166.

27. Coutinho RZ, Miranda-Ribeiro P. Religião, religiosidade e iniciação sexual na adolescência e juventude: lições de uma revisão bibliográfica sistemática de mais de meio século de pesquisas. Rev. bras. estud. popul. [Internet]. 2014 [acesso em 10 nov 2017]; 31(2). Disponível em: http://dx.doi.org/10.1590/S010230982014000200006.

28. Heinisch RH, Stange LJ. Religiosidade e doenças cardiovasculares. Arq catarin. med. [Internet]. 2014 [acesso em 10 nov 2017]; 43(4). Disponível em: https://www.researchgate.net/publication/281650769 Religiosidade e doencas cardiovasculares Religiousness and cardiovascular diseases.

29. Abdala GA, Kimura M, Duarte YAO, Lebrão ML, Santos B. Religiosidade e qualidade de vida relacionada à saúde do idoso. Rev. Saúde Públ. [Interenet]. 2015 [acesso em 10 nov 2017]; 49:55. Disponível em: http://www.scielo.br/pdf/rsp/v49/pt 0034-8910-rsp-S0034-89102015049005416.pdf.

30. Santos ARM, Oliveira LMFT, Farias Júnior JC, Silva PPC, Silva EAPC, Freitas, C. Associação entre prática religiosa e comportamentos de risco à saúde em adolescentes de Pernambuco, Brasil. Rev. bras. ativ. fís. saúde. [Internet]. 2015 [acesso em 10 nov 2017]; 20(3). Disponível em: https://doi.org/10.12820/ rbafs.v.20n3p284.

31. Silva SK, Passos SMK, Souza LDM. Associação entre religiosidade e saúde mental em pacientes com HIV. Psicol. teor. prat. [Internet]. 2015 [acesso em 10 nov 2017]; 17(2). Disponível em: http://pepsic. bvsalud.org/scielo.php?script=sci arttext\&pid=S1516-36872015000200003.

32. Alves DA, Silva LG, Delmondes GA, Lemos ICS, Kerntopf MR, Albuquerque GA. Cuidador de criança com câncer: religiosidade e espiritualidade como mecanismos de enfrentamento. Rev. Cuid [Internet]. 2016 [acesso em 10 nov 2017]; 7(2). Disponível em: https://doi.org/10.15649/cuidarte.v7i2.336.

33. Reinaldo AMS, Santos RLF. Religião e transtornos mentais na perspectiva de profissionais de saúde, pacientes psiquiátricos e seus familiares. Saúde debate. [Internet]. 2016 [acesso em 10 nov 2017]; 40(110). Disponível em: http://dx.doi.org/10.1590/0103-1104201611012.

34. Agorastos A, Demiralay C, Huber C. Influence of religious aspects and personal beliefs on psychological behavior: focus on anxiety disorders. Psychol Res Behav Manag [Internet]. 2014 [acesso em 22 out 2017]; (7). Disponível em: https://doi.org/10.2147/PRBM.S43666.

35. Koenig HG, King D, Carson V. The handbook of religion and health. 2nd. ed. New York: Oxford University Press; 2012.

36. Moreira-Almeida A, Pinsky I, Zaleski M, Laranjeira R. Religious involvement and sociodemographic factors: a Brazilian national survey. Rev. Psiquiatr. clin. [Internet]. 2010 [acesso em 22 out 2017]; 37(1). Disponível em: http://dx.doi.org/10.1590/S0101-60832010000100003.

37. Evangelista CB, Lopes MEL, Costa SFG, Abrão FMS, Batista PSS, Oliveira RC. Espiritualidade no cuidar de pacientes em cuidados paliativos: um estudo com enfermeiros. Esc. Anna Nery. [Internet]. 2016 [acesso em 10 nov 2017]; 20(1). Disponível em: http://dx.doi.org/10.5935/1414-8145.20160023. 
38. Alves RRN, Alves HN, Barboza RRD, Souto WMS. The influence of religiosity on health. Cienc. saude colet. [Internet]. 2010 [acesso em 10 nov 2017]; 15(4). Disponível em: https://www.ncbi.nlm.nih.gov/ pubmed/20694332.

39. Abdala GA, Rodrigues WG, Torres A, Rios MC, Brasil MS. A religiosidade/espiritualidade como influência positiva na abstinência, redução e/ou abandono do uso de drogas. REVER. [Internet]. 2010 [acesso em 22 out 2017]; (10). Disponível em: http://pucsp.br/rever/rv1_2010/i_abdala.pdf.

40. Kim NY, Huh HJ, Chae JH. Effects of religiosity and spirituality on the treatment response in patients with depressive disorders. Compr. Psychiatry [Internet]. 2015 [acesso em 22 out 2017]; 60(1). Disponível em: http://dx.doi.org/10.1016/j.comppsych.2015.04.009.

41. Rassoulian A, Seidman C, Löffler-Stastka, H. Transcendence, religion and spirituality in medicine: Medical students' point of view. Medicine. [Internet]. 2016 [acesso em 22 out 2017]; 95(38). Disponível em: http://dx.doi.org/10.1097/MD.0000000000004953.

42. Sanders L, Kopis S, Moen C, Pobanz A, Volk F. Perceptions of Spirituality and Spiritual Care in Religious Nurses. J Christ Nurs. [Internet]. 2016 [acesso em 22 out 2017]; 33(4). Disponível em: http:// dx.doi.org/10.1097/CNJ.0000000000000308.

43. Almeida AM, Koening HG, Lucchetti G. Clinical implications of spirituality to mental health: review of evidence and practical guidelines. Rev Bras Psiquiatr. [Internet]. 2014 [acesso em 22 out 2017]; 3(6). Disponível em: https://www.ncbi.nlm.nih.gov/pubmed/24839090.

Recebido: 02/04/2018

Finalizado: 25/01/2019

Autor Correspondente:

Priscila Cristina da Silva Thiengo

Universidade do Estado do Rio de Janeiro

Bvd. 28 de Setembro, 157 - 20551-030 - Rio de Janeiro, RJ, Brasil

E-mail: profprithiengo@gmail.com

Contribuição dos autores:

Contribuições substanciais para a concepção ou desenho do estudo; ou a aquisição, análise ou interpretação de dados do estudo - PCST, AMTG, MCM, PLSC, LCMF, ANS

Elaboração e revisão crítica do conteúdo intelectual do estudo - AMTG, MCM, PLSC, LCMF, ANS 